\title{
MEASURING URBAN RESILIENCE USING CLIMATE DISASTER RESILIENCE INDEX (CDRI)
}

\author{
W. N. M. Wan Mohd Rani ${ }^{1 *}$, K. H. Kamarudin ${ }^{1,}$ K. A. $\operatorname{Razak}^{2,3}$, R. Che Hasan ${ }^{1}$, Zakaria Mohamad ${ }^{3}$ \\ ${ }^{1}$ Razak Faculty of Technology and Informatics, Universiti Teknologi Malaysia, Kuala Lumpur \\ ${ }^{2}$ Disaster Preparedness and Prevention Center, Malaysia-Japan International Institute of Technology, Universiti Teknologi Malaysia \\ Kuala Lumpur \\ ${ }^{3}$ Geomapping Technology Sdn Bhd / Society for Engineering Geology and Rock Mechanics \\ *Corresponding Author: wnurul.kl@utm.my
}

KEY WORDS: Climate Disaster Resilience Index (CDRI), Climate Resilience, Disaster Resilience, Resilient City

\begin{abstract}
:
Measuring urban resilience is one of the important processes toward understanding the current and potential future risk of cities to guide the development of suitable policies and strategies related to climate and disaster resilience. Climate Disaster Resilience Index (CDRI) is one of the means to measure urban resilience. CDRI has been adopted at international level and Kuala Lumpur was one of the tested cities. However, in this study the use of CDRI was adjusted by type of disaster, local needs, and the specific study objectives. A comprehensive assessment of all components that include the physical, social, economic, institutions and the environment component were performed to capture the current performance of the case study cities to cope with disasters. This paper aims at testing the CDRI and exploring the importance of measuring urban resilience to gain awareness on the current and potential future risk for better disaster risk management. Findings from the CDRI assessment performed on two cities; Kajang and Ampang Jaya, situated in the state of Selangor were presented. The paper also highlights the underlying factors that inhibit resilience and means on improving the future disaster management and planning of Malaysian cities to become a disaster resilient city. In conclusion, the data obtained from the CDRI assessment able to guide the establishment of Urban Resilience Action Plan for these cities.
\end{abstract}

\section{INTRODUCTION}

Achieving climate and disaster resilient cities have become a global agenda today that have gained much attention over recent years. The increase in the events of natural and man-induced disasters have led to higher awareness on the need to move towards disaster and climate resilient cities. Cities and its entire system are vulnerable to the impacts of climate change and calamities that may occur naturally or man-made. The recent episode of disasters have highlighted that cities are not prepared to face disasters and climate related events. However, in any condition, cities need to continuously maintain its function to provide protection to the people and the facilities. Different cities of different location and feature responds in its own ways whenever a disaster or catastrophe strikes. Understanding and communicating risk is one of the key approach highlighted by the United Nation Development Programme (UNDP) and Hyogo Framework for Action (HFA) to ensure holistic decision-making and integrated policies strategies to become more resilient (UNDP, 2015). The need to understand the current condition and level of resilience will help the city to better prepare in situations where frequency of disasters are becoming more common with greater intensity.

Previous studies have stated that the process of making a disaster resilient city is complex due to its nature of multidisciplinary and multi-level approach. This issue also applies to Malaysian cities. The collaboration and input of various stakeholders are crucial to integrate the climate change adaptation (CCA) and disaster risk reduction (DRR) measures to achieve disaster resilient cities. In line with this, this paper aims at exploring on the importance of measuring urban resilience to gain awareness on the current and potential future risk for better disaster risk management. The paper presents findings from the CDRI assessment performed on two cities; Kajang, and Ampang Jaya, Selangor. The paper also highlights the underlying factors that inhibit resilience and means on improving the future disaster management and planning of Malaysian cities to achieve disaster resilient cities.

\section{URBAN RESILIENCE}

According to The Rockefellar Foundation (2016), urban or city resilience refers to the capacity of cities to function, so that the people living and working in cities - particularly the poor and vulnerable - survive and thrive no matter what stresses or shocks they encounter. This character is most important for cities because cities are the centre of most economic activities. Any disruption to these activities will contribute to the loss of many sectors. Hence, to become a resilient city, all actors within the urban system must have the ability to bounce back, adapt, and recover from any shock and disaster within a certain period to minimize the economic, environmental and social loss.

Measuring urban resilience is one of the important processes towards understanding the current and potential future risk of cities to guide the development of suitable policies and strategies related to climate and disaster resilience. However, the process of measuring and mapping the level of urban resilience is a challenge for Malaysia, as it requires commitment and collaboration of various stakeholders. Lack of coordinated data and information are also an issue because of the bureaucratic of different agencies. Based on the discussions held with several technical agencies, it was revealed that technical data and information related to understanding the risks of selected areas was provided to local government has not been 
fully utilized in establishing the planning policies, guidelines and strategies (Field Survey, 2017). This indicates the lack of knowledge and awareness to integrate measures of CCA and DRR into the process of development planning to mitigate and prevent future disaster risk. This issue is also highlighted in a recent research conducted to assess the integration of climate change aspects into spatial planning in the UK (Carter \& Sherriff, 2016). Carter and Sherriff (2016) suggested that the adaptation measures shall be in the form of constituent element of designing and governing the cities that will allow it to support and progress hand-in-hand with the key urban agenda such as improve the quality of life and enhance the competitiveness of cities.

To date, one of the preferred method in measuring the level of resilience is the Climate and Disaster Resilience Index (CDRI) initiated by Kyoto University in collaboration with CITYNET, Tokyo Distance Learning Centre of the World Bank Sustainable Environment and Ecological Development Society and UNISDR (Shaw et al. 2010). However, it is important to note that the index/rating is not to make comparison between cities but it is to assess the city's performance on resilience over time. This allows the relevant authority to perform and monitor progress of resilience level.

\subsection{What is Climate Disaster Resilience Index?}

Climate Disaster Resilience Index is a tool aimed at measuring the city's level of resilience. The application to aimed to create awareness of the current and future risk that may pose the city (Joerin \& Shaw, 2011; Surjan, Sharma, \& Shaw, 2011). Outcome of the assessment is expected to guide in the establishment of a more holistic and comprehensive climate and disaster management plan to address the related issues.

Measuring and mapping the level of resilience is the key step that enables stakeholders to understand and assess the city's current and future potential climate/disaster-related risks. The outcome of the process will lead to developing a baseline measurement of the current level of resilience (UNISDR 2015). This process is important to identify priorities for the development of policies, strategies and actions. Four sectors that consist of the economy, society, environment and institutions are the main drivers of resilient cities (OECD 2016). These drivers have become the key variables in measuring and assessing the climate disaster resilience level of cities prior to the establishment of strategies that addresses the current situation and context (Shaw et al. 2010; Joerin et al. 2011). In the year 2010, Kuala Lumpur was one of the eight cities participated in the resilience mapping coordinated by UNISDR (Shaw et al., 2010). The CDRI assessment conducted on Kuala Lumpur revealed moderate resilience rating for social, economic, institutional, and natural. However, for the physical component revealed a higher resilience with score above 4.00 . Findings from the resilience mapping indicated that Kuala Lumpur need to further mainstream DRR and CCA measures into the respective development plans to ensure continuous effort with support of adequate resources (Shaw et al., 2010).

\section{METHODOLOGY}

The study selected two cities within the Klang Valley as the case study for the CDRI tool; Kajang and Ampang Jaya, Selangor. These two cities vary in topographical, geographical and its morphology. Furthermore, these two cities were selected because of its potential risk to disasters i.e. flooding and landslide. According to the National Physical Plan 3, Kajang is one of the cities in Malaysia that are prone to flooding specifically flashflood and Ampang Jaya has high exposure to landslide (Federal Department of Town and Country Planning Peninsular Malaysia, 2017). The assessment is based on the five components of the CDRI; physical, social, economy, institutional, and natural with 25 sub-components and 125 indicators (Refer Table 1).

\begin{tabular}{|c|c|}
\hline Components & Subcomponents \\
\hline \multirow[t]{5}{*}{ Physical } & Electricity \\
\hline & Water \\
\hline & Sanitation and Solid Waste Disposal \\
\hline & Accessibility of Roads \\
\hline & Housing and Land Use \\
\hline \multirow[t]{5}{*}{ Social } & Population \\
\hline & Health \\
\hline & Education and Awareness \\
\hline & Social Capital \\
\hline & Community Preparedness \\
\hline \multirow[t]{5}{*}{ Economy } & Income \\
\hline & Employment \\
\hline & Household Assets \\
\hline & Finance and Savings \\
\hline & Budget and Subsidy \\
\hline \multirow[t]{5}{*}{ Institutional } & Mainstreaming of DRR and CCA \\
\hline & Effectiveness of city's crisis management \\
\hline & $\begin{array}{l}\text { Effectiveness of a city's institution to } \\
\text { respond to a disaster }\end{array}$ \\
\hline & $\begin{array}{l}\text { Institutional collaboration with other } \\
\text { organisations and stakeholders }\end{array}$ \\
\hline & Good Governance \\
\hline \multirow[t]{5}{*}{ Natural } & Intensity/ Severity of natural hazards \\
\hline & Frequency of natural hazards \\
\hline & Ecosystem services \\
\hline & Land-use in natural terms \\
\hline & Environmental security and food security \\
\hline
\end{tabular}

Table 1: Components and sub-components of CDRI. Source: Shaw et al. (2010)

The information was gathered through the questionnaire survey form distributed to key informants of respective agencies involved in the planning and development of cities and disaster risk management. Respondents were required to respond to the parameters based on the five-point Likert scale where 1 refers to the lowest score/value and 5 indicates highest score/value. The analysis is based on the mean scores reported by all components and subcomponents to capture the level of readiness and resilience of the selected cities in coping the current risk and preparing for future disaster risk.

\section{FINDINGS \& ANALYSIS}

\subsection{The Profile of Cities}

\subsubsection{Kajang, Selangor}

The town of Kajang covers an area of 6,699 hectares with population size of 413,613 inhabitants. The town is bordered by four sub-districts (or Mukim) namely Mukim of Cheras, Ulu Semenyih, Semenyih and Kajang (GPPDRC, 2017; PlanMalaysia, 2017). In terms of land use distributions, the 
town of Kajang and its surrounding areas are highly populated and urbanised. Land use for housing is the largest land use for Kajang $(30.31 \%)$, followed by transportation (23.64\%), industrial $(8.13 \%)$, public amenities $(7.55 \%)$, commercial $(3.03 \%)$ and others $(1.68 \%)$. With high rate of urban development, many parts of Kajang have low water retention level.

According to National Physical Plan, the town of Kajang has been identified as one of area with high potential for flooding. Review of Local Plan of Kajang 2035 (Rancangan Tempatan MPKJ 2035) indicated that the major river i.e. Langat River and other tributaries namely Sg. Long, Sg. Sekamat, Sg. Cheras dan Sg. Perimbun; which flow through the town of Kajang (refer Figure) are directly contributing to the formulation of big flood plain area covering all four sub-districts and $90 \%$ of Kajang town. This is also the main reason for having Kajang town as Environmentally Sensitive Area (ESA/KSAS) with flood risk and the exposure to disaster risk is reported to be at average (refer Figure 3).

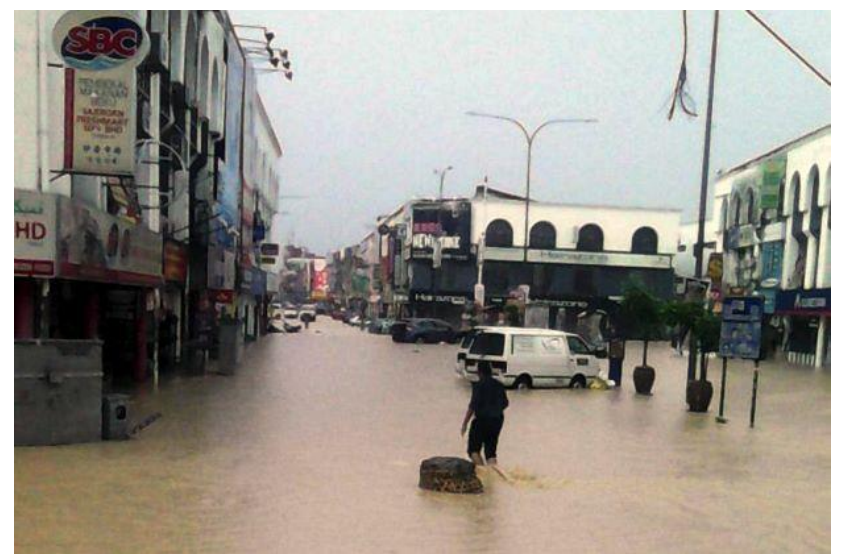

Figure 1: Image of flood in the commercial area of Kajang Town

Source: Bernama (2014, November 12). Flash floods hit Kajang, The Star Online. Retrieved from https://www.thestar.com.my

The frequent occurrences of flash flood in Kajang town resulted in many commercial premises and Kajang market to submerge up to one metre hence disrupting daily activities (refer Figure 1). In average, flash flood occurred after 30 minutes to two hours of rain. In 2017, three major flash floods were recorded in September 29, November 12 and December 20. Few main commercial hubs that usually affected including Plaza Metro Kajang and Hong Leong Bank. In addition, few residential areas nearby Semenyih, Sungai Kantan and Jalan Semenyih also experienced flash floods resulted in evacuation of people and temporary closure of local businesses.

\subsubsection{Ampang Jaya, Selangor}

Ampang Jaya covers an area approximately 6,527 hectare with a population of 470,792 people and the exposure to disaster risk is at average (refer Figure 3). The area is under the management of sub-district (Mukim) of Hulu Klang and Ampang. Housing and residential development representing $44.83 \%$ of total land use for Ampang, followed by transportation (21.12\%), open space and recreation $(9.93 \%)$ and others. From the context of topography, the distribution of high-elevated areas mostly concentrated in the east part of the town and Hulu Kelang, resulted in occurrences of few landslide incidents. According to Local Plan for Ampang 2020 (Rancangan Tempatan Ampang) published by Ampang Jaya Municipality, the eastern part of Mukim Hulu Klang is mostly conservation area of Ampang Forest Reserve (and also part of Selangor State Park) with a total area of 8,591 hectare. There are many settlements resides at hilltop and hillslopes (more than 25 degree/Class 3 ) including Taman Zoo View and Bukit Antarabangsa. The most tragic and high profiled landslide disaster in Ampang area was the collapse of Block 1, Highland Towers condominium in Taman Hillview, Hulu Kelang. The event occurred on December $11^{\text {th }} 1993$ and until today remains as the nations' worst landslide disaster since independence with official number of casualties of 48 victims (refer Figure 2). Consequently, the area was declared not safe, and the remaining residents of Block 2 and Block 3 were evacuated and resettled in other places.

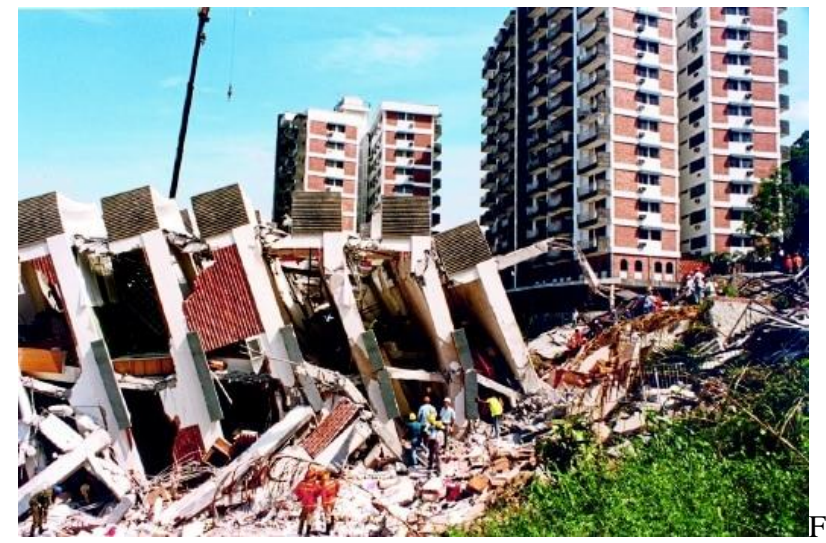

igure 2: Image of the collapsed Highland Towers residential building in Ampang Jaya in 1993

Source: David Adrian (2016, March 20). The day the tower collapsed. New Straits Times. Retrieved from https://www.nst.com.my

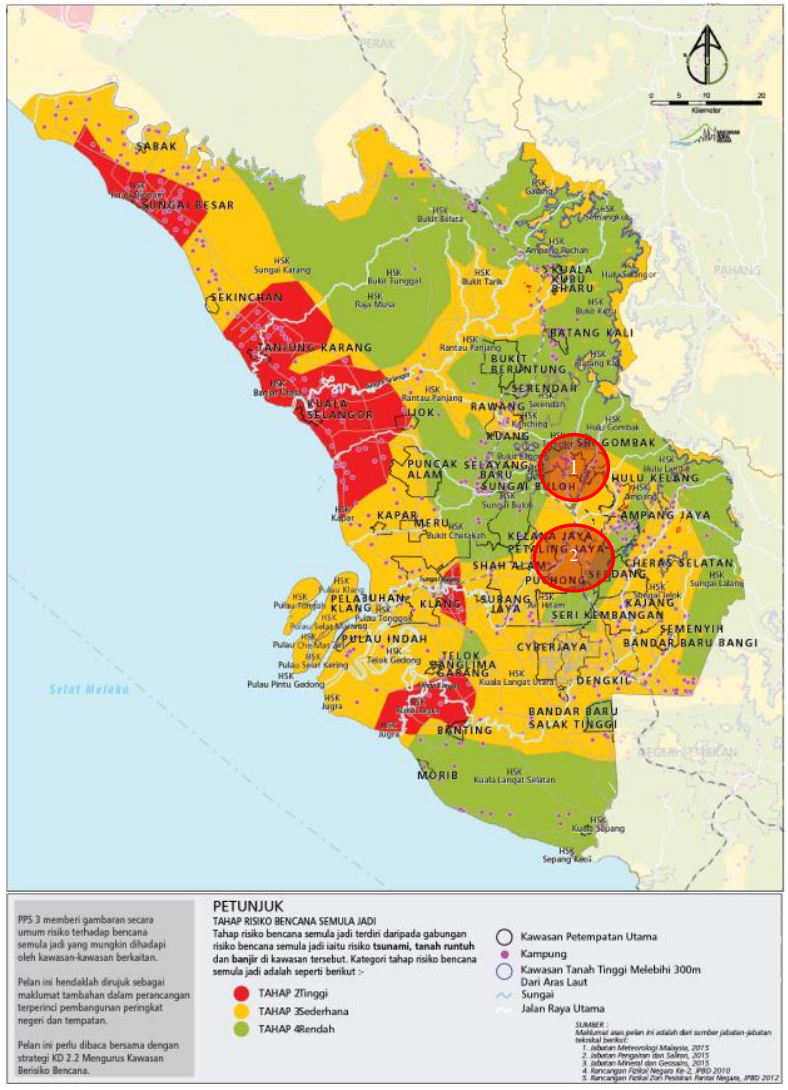

Figure 3: Level of disaster risk of the two study areas 
* 1 : Ampang Jaya

$* 2$ : Kajang

Source: Review of Local Plan of Kajang 2035 (Rancangan Tempatan MPKJ 2035)

\subsection{The Level of Resilience}

The previous section has provided a glimpse of the two case study areas on the existing situation, which indicate they fall within the category of average in terms of the disaster risk level. Based on the outcome of the CDRI assessment, the strength and weakness of the cities understudy are revealed. Overall, the two case study cities showed a similar pattern with the highest score to be reported for the physical component, and the least score was recorded for economy component with 3.12 (Kajang) and 3.17 (Ampang) accordingly.

\begin{tabular}{|l|c|c|c|c|c|}
\hline City & Physical & Social & Economy & Institutional & Natural \\
\hline Kajang & 4.23 & 3.78 & 3.12 & 3.41 & 3.84 \\
\hline Ampang & 4.04 & 3.52 & 3.17 & 3.55 & 3.61 \\
\hline
\end{tabular}

Table 2: Overall CDRI Analysis. Source: Research fieldwork CDRI Survey, 2017

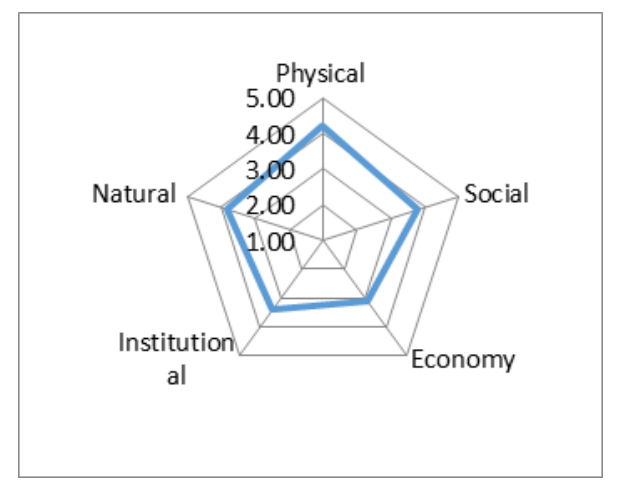

Figure 1: CDRI Analysis (Kajang)

Source: Research fieldwork - CDRI Survey, 2017

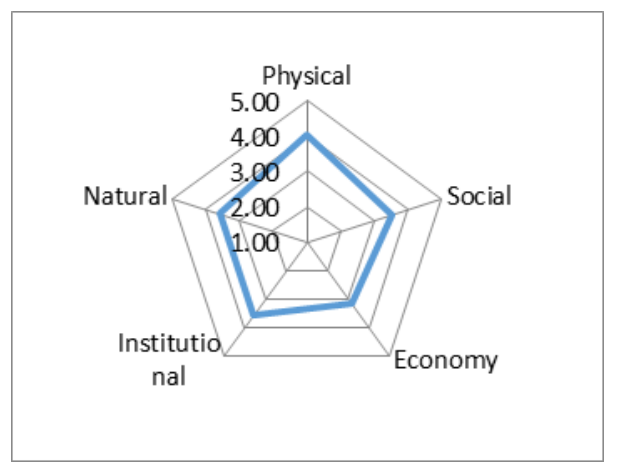

Figure 2: CDRI Analysis (Ampang Jaya)

Source: Research fieldwork - CDRI Survey, 2017

\subsubsection{Physical}

The CDRI assessment on the physical component revealed a moderately high score for both Kajang and Ampang with an average score of 4.13. The electricity and water were recorded to have higher resilience scores because of the continuous supply even during the flooding events (Field Survey, 2017). On the other hand housing and land use were reported to score lower due to the high density and compactness of the Kajang town that have led to other problems such as overcrowding and traffic congestion within the city.

\begin{tabular}{|l|c|c|}
\hline Parameters & Kajang & Ampang \\
\hline Electricity & 4.58 & 4.71 \\
\hline Water & 4.73 & 4.35 \\
\hline Sanitation and solid waste disposal & 3.72 & 3.94 \\
\hline Accessibility of roads & 4.32 & 3.96 \\
\hline Housing and land use & 3.80 & 3.27 \\
\hline
\end{tabular}

Table 3: Assessment of Physical Component . Source: Research fieldwork - CDRI Survey, 2017

\subsubsection{Social}

For social component, the assessment involved parameters such as population, health, education and awareness, social capital and community preparedness during a disaster (Shaw et al., 2010). Based on the assessment performed in both cities, education and awareness were reported to have the highest score with 4.13 (Kajang) and 3.96 (Ampang). Lowest rating was reported from the aspect of population. In terms of population, Kajang and Ampang are known to be among the areas of high population density within the Greater Kuala Lumpur vicinity. Aspects of health and the preparedness of the community also revealed to be moderate for both cities.

\begin{tabular}{|l|c|c|}
\hline Parameters & Kajang & Ampang \\
\hline Population & 3.40 & 3.06 \\
\hline Health & 3.77 & 3.44 \\
\hline Education and awareness & 4.13 & 3.96 \\
\hline Social capital & 3.87 & 3.60 \\
\hline $\begin{array}{l}\text { Community preparedness during a } \\
\text { disaster }\end{array}$ & 3.73 & 3.53 \\
\hline
\end{tabular}

Table 4: Assessment of Social Component. Source: Research fieldwork - CDRI Survey, 2017

\subsubsection{Economic}

Overall, the economic resilience of Kajang and Ampang Jaya were reported to be on average. However, in comparison to other components, the economic component reported the lowest rating. For Kajang, higher scores are on three main components; income, employment and household asset ownership. These three components reported to achieve satisfactory rating. This indicates that the city's economy able to recover after facing a flood disaster. Meanwhile, Ampang Jaya is known to be one of the rapidly growing region with various economic activities also reveal to achieve satisfactory score on the three main economic subcomponent. However, two other sub-components; finance and savings and budget and subsidy achieved a relatively low score for both cities. The assessment conducted in 2010 for Kuala Lumpur also indicated the same pattern. The lack of credit facility and disaster risk financing are among the reasons that have contributed to the low scores (Field Survey, 2017). Hence, it is highly suggested that the local government and related stakeholders to play a greater role particularly in allocating certain amount of fund and provide assistance to local economy for business continuity after disaster. 


\begin{tabular}{|l|c|c|}
\hline Parameters & Kajang & Ampang \\
\hline Income & 3.52 & 3.19 \\
\hline Employment & 3.83 & 3.69 \\
\hline Household assets & 3.47 & 3.46 \\
\hline Finance and savings & 2.55 & 2.68 \\
\hline Budget and subsidy & 2.29 & 2.82 \\
\hline
\end{tabular}

Table 5: Assessment of Economic Component. Source: Research fieldwork - CDRI Survey, 2017

\subsubsection{Institutional}

The institutional component is assessed in more detail with assessment on the sub-components such as mainstreaming DRR and CCA in the development plans, the city's effectiveness in managing the crisis and respond to disaster. For Kajang, the highest score was reported for the institution's effectiveness in responding to disasters. The scores implies the need to focus on the governance in managing future disasters. Nonetheless, presently, the local authority has taken great initiatives in dealing with the frequent flashflood. Measures such as earlywarning system, infrastructural intervention and awareness have been in place, which contributed to the high rating. On the other hand, for Ampang Jaya, institutional collaboration with other organisations and stakeholders ranked highest with score 3.86. The high-profile landslide involving the collapse of apartment building in year 1993 has gained a lot of attention throughout the nation. This gave the opportunity for collaboration with various agencies in dealing with issues of the landslide risk within area. Low ratings for both cities were reported for the effort to mainstream and implement DRR and CCA in the development plans. In addition, the two cities lack on the early warning systems and the implementation of disaster drills (Field Survey, 2017).

\begin{tabular}{|l|c|c|}
\hline Parameters & Kajang & Ampang \\
\hline Mainstreaming of DRR and CCA & 2.83 & 3.14 \\
\hline $\begin{array}{l}\text { Effectiveness of city's crisis } \\
\text { management framework }\end{array}$ & 3.83 & 3.85 \\
\hline $\begin{array}{l}\text { Effectiveness of city's institutions to } \\
\text { respond to a disaster }\end{array}$ & 3.87 & 3.76 \\
\hline $\begin{array}{l}\text { Institutional collaboration with other } \\
\text { organisations and stakeholders }\end{array}$ & 3.82 & 3.86 \\
\hline Good governance & 2.72 & 3.15 \\
\hline
\end{tabular}

Table 6: Assessment of Institutional Component. Source: Research fieldwork - CDRI Survey, 2017

\subsubsection{Natural}

The assessment on the natural component includes measures of intensity, severity and frequency of hazard, ecosystems services, land-use in natural terms and the environmental policy in place. Findings indicate that both cities are resilience in terms of intensity and frequency of hazard. The disasters that have striked in both cities are more of man-induced disasters. The flooding events in Kajang are caused by the rapid urbanization coupled with the factor of its floodplain location and poor stormwater management. Whereas, the occurrence of landslide Ampang Jaya is also due to the development of residential buildings on hilly slope that have altered the natural feature of the environment. This situation is reflected in the moderately low rating on the sub-component of land use with the mean score of 2.76. However, the moderate rating of environmental policy and food security seems to have no correlation with other sub-components.

\begin{tabular}{|l|c|c|}
\hline Parameters & Kajang & Ampang \\
\hline Intensity of hazard & 4.55 & 4.49 \\
\hline Frequency of hazard & 4.60 & 4.52 \\
\hline Ecosystems services & 3.15 & 2.77 \\
\hline Land-use in natural terms & 2.98 & 2.76 \\
\hline $\begin{array}{l}\text { Environmental policy and food } \\
\text { security }\end{array}$ & 3.93 & 3.49 \\
\hline
\end{tabular}

Table 6: Assessment of Natural Component. Source: Research fieldwork - CDRI Survey, 2017

\section{SUMMARY \& CONCLUSION}

Based on the findings of the CDRI assessment performed on the two case study cities of Kajang and Ampang Jaya revealed that the resilience level of these cities are at average. Actions need to be taken to improve the resilience and prepare these cities to face the future risks. In the meantime, several key strategies can be recommended as the basis to formulate an action plan. Ultimately, towards achieving climate and disaster resilience it is important to ensure the incorporation of disaster risk and climate risk assessments into the planning and management, revision of existing development policies to include measures of DRR, continuously monitor and assess developments in highrisk areas and finally to ensure successful collaboration of various stakeholders involved. The information obtained through the CDRI assessment is to act as a baseline. In addition, the CDRI assessment is recommended to be reviewed within an interval of every 2 to 5 years to monitor the progress and success of actions and strategies formulated with reference to the initial CDRI assessment conducted. Hence, technical agencies with the primary role of capturing data and information related to the elements at risk need to assist local governments to ensure that any developments especially within high-risk areas are reviewed and planned with measures of DRR and CCA and up-to-date risk information. This approach was adopted by the UNISDR where the team reviewed the CDRI exercise after three years. Among the twelve cities assessed, Makati, Thailand reported to progress well as compared to other cities.

In terms of financial support, the lack of credit facility and disaster risk financing for the two case study cities indicate that credit facilities need to be improved to allow local community within disaster prone areas to have options in the preparation to face with any future disasters. Also, an educated population with high awareness on disaster and climate resilience is essential to enable a more holistic approach to build a culture of safety and resilience at all levels within the city. Subsequently, the efforts shall also focus on to strengthen the institutional capacity in ensuring policies and strategies are implemented efficiently.

Lastly, with the resilience mapping it is hoped that the local authority to develop Urban Resilience Action Plan as applied by other cities that have established similar resilience mapping. In general, the aim of such Urban Resilience Action Plan is to improve disaster risk management and the city's resilience. 


\section{ACKNOWLEDGEMENTS}

The authors would like to express sincere gratitude to the Federal Department of Town and Country Planning, Peninsular Malaysia (PLANMalaysia), Environmental Planning Group Sdn. Bhd. (EPG) for the opportunity to be part of the research team in the preparation for the Planning Guidelines for Disaster Resilient Cities. The authors would also like to acknowledge Ministry of Education Malaysia, Universiti Teknologi Malaysia (UTM) and the research Management Centre (RMC) of UTM for providing the financial support for this paper to be published. This paper is financed by the UTM Razak School for research funding.

\section{REFERENCES}

Bernama (2014, November 12). Flash floods hit Kajang, The Star Online. Retrieved from https://www.thestar.com.my

Carter, J., \& Sherriff, G. (2016). Adapting to Climate Change: Getting More from Spatial Planning. 131-144. doi:10.1007/9783-319-25814-0_10

David Adrian (2016, March 20). The day the tower collapsed. New Straits Times. Retrieved from https://www.nst.com.my

Federal Department of Town and Country Planning Peninsular Malaysia, (2017), National Physical Plan 3

Field Survey, 2017.

Economic Planning Unit (2015), Eleventh Malaysia Plan 20162020, Anchoring Growth on People, Economic Planning Unit, Prime Minister's Department Malaysia,

Joerin, J., \& Shaw, R. (2011). Chapter 3 Mapping Climate and Disaster Resilience in Cities. 6, 47-61.

OECD. (2016). "Resilient Cities Policy Highlights of the OECD Report.

Government of Malaysia (2017), National Physical Plan 3. Review of Local Plan of Kajang 2035 (Rancangan Tempatan MPKJ 2035)

Shaw et al. (2010) Climate and disaster resilience initiative Capacity-building program. UNISDR.

Surjan, A., Sharma, A., \& Shaw, R. (2011). Chapter 2 Understanding Urban Resilience. 6, 17-45.

The Rockefeller Foundation and ARUP (2016), City Resilience Index: Understanding and Measuring City Resilience. Retrieved from: https://assets.rockefellerfoundation.org

UNDP (2015), UNDP and the Hyogo Framework for Action, 10 Years of Reducing Disaster Risks. United Nations Development Programme

UNISDR. (2012). How to Make Cities More Resilient- A Handbook for Local Government Leaders. Geneva: United Nations.

UNISDR. (2015). Sendai Framework for Disaster Risk Reduction 2015-2030. Retrieved from
UNISDR. (2017). How to Make Cities More Resilient- A Handbook for Local Government Leaders. Retrieved from Geneva:

Revised August 2018 